\title{
ANALISIS KONDUKTIVITAS PANAS PADA MATERIAL ALTERNATIF SEBAGAI INSULASI DINDING RUANG AKOMODASI KAPAL BERBASIS LIMBAH AMPAS TEBU DAN SERBUK KAYU
}

\author{
Aurista Miftahatul Ilmah", Tristiandinda Permata, Jailani \\ ${ }^{1}$ Teknik Bangunan Kapal, Politeknik Negeri Madura, Sampang, Madura, Indonesia \\ "e-mail: aurista.ilmah@gmail.com
}

\begin{abstract}
ABSTRAK
Ruang akomodasi pada kapal digunakan sebagai tempat peristirahatan bagi crew dan sebagai tempat penyimpanan barang di kapal sehingga dibutuhkan insulasi disetiap ruangan untuk menahan rambatan panas pada kapal. Jenis material insulasi pada kapal salah satunya adalah mineral wool yang bahan dasar pembuatannya adalah Polyurethane. Polyurethane merupakan busa plastik padat campuran polyol dan isocynate dan salah satu bahannya berbahan polimer dimana bisa diperoleh dari bahan alam yang mengandung banyak selulosa seperti ampas tebu dan serbuk kayu. penambahan serbuk kayu dan ampas tebu yang dapat dilakukan adalah 40\% dari total volume bahan campuran. Kemudian dilakukan pengujian umtuk mendapatkan nilai konduktivitas termal dari masing-masing campuran serbuk kayu, ampas tebu, dan polyurethane dengan berbagai variasi perbandingan takaran pada serbuk kayu, untuk selanjutnya dilakukan perhitungan beban pendingin. Hasil pengujian menunjukkan nilai konduktivitas terbaik adalah pada pencampuran serbuk kayu 0,2 gr yaitu 2,65 w/mk yang dapat menahan laju panas sampai $311,59 \mathrm{KW}$.
\end{abstract}

Kata Kunci: Ampas tebu; Serbuk kayu; Komposit; Insulasi; Konduktivitas Termal.

\begin{abstract}
[Title : Thermal Conductivity Analysis of Alternative material as Insulation of Ship Accommodation Room based on Baggase and Sawdust] The accommodation room on the ship is used as a resting place for the crew and as a storage place for goods on the ship so insulation is needed in each room to withstand the heat propagation on the ship. One type of insulation material on a ship is mineral wool which is made from polyurethane. Polyurethane is a plastic foam that is a mixture of polyol and isocynate and one of the ingredients is polymer which can be obtained from natural materials that contain lots of cellulose such as bagasse and sawdust. the addition of sawdust and bagasse that can be done is $40 \%$ of the total volume of the mixture. Then it is carried out to get the thermal conductivity value of each mixture of sawdust, bagasse, and polyurethane with various dosing ratios on the sawdust, to further calculate the cooling load. The test results show the best conductivity value is the mixing of wood powder $0.2 \mathrm{gr}$ which is $2.65 \mathrm{~W} / \mathrm{mk}$ which can withstand the rate of heat up to $311.59 \mathrm{KW}$.
\end{abstract}

Keywords: Baggase; Sawdust; Composite; Insulation; Thermal Conductivity.

\section{PENDAHULUAN}

Seiring perkembangan jaman insulasi banyak digunakan sebagai isolasi (pembuat kedap) untuk berbagai tujuan salah satunya sebagai penahan panas pada suatu bangunan. Salah satu bangunan yang memanfaatkan insulasi termal adalah kapal. Salah satu ruangan di kapal yang membutuhkan insulasii adalah ruang akomodasi, ruangan ini digunakan sebagai tempat penyimpanan barang yang ada dii kapal sehingga dibutuhkan insulasi untuk menahan rambatan panas pada kapal tersebut.
Jenis material insulasi yang digunakan pada kapal salah satunya adalah polyurethane. Polyurethane merupakan jenis polimer yang terdiri dari campuran polyol dan isocyanate yang digunakan dalam penyekat panas yang membutuhkan perlindungan terhadap panas langsung. Salah satu bahan polyurethane berbahan polimer dari alam yang banyak mengandung selulosa adalah ampas tebu dan serbuk kayu.

Ampas tebu adalah suatu residu dari proses penggilingan tanaman tebu setelah diekstrak atau diambil niranya sehingga tersisa limbah serat dari 
tanaman tebu itu sendiri. Tebu yang sudah diambil airnya akan menghasilkan ampas yang dapat mengotori lingkungan. Banyak orang yang tidak tahu bahwasanya ampas tebu memiliki kandungan selulosa 52,7\%, hemiselulosa 20,0\%,dan lignin $24,2 \%$. Samsuri et al.,(2007) yang dapat dimanfaatkan sebagai bahan pendukung sebuah campuran material. Seperti halnya ampas tebu, serbuk kayu gergaji merupakan limbah yang diperoleh dari industri-industri kayu yang dapat mencemari lingkungan, serbuk kayu gergaji juga mengandung selulosa yang bisa dimanfaatkan sebagai bahan pendukung seperti pada ampas tebu. Kandungan serbuk kayu gergaji mempunyaii selulosa sebesar 60\%, lignin 28\% dan zat lain (termasuk zat gula) 12\%. Baharudin (2005).

Berdasarkan hal-hal di atas maka perlu dilakukan pengkajian sejauh mana ampas tebu dan serbuk kayu dapat dijadikan sebagai material alternatif. Oleh karena itu dibutuhkan uji konduktifitas termal untuk campuran ampas tebu, serbuk gergaji, dan polyurethane. Dengan dilakukannya penelitian ini diharapkan limbah ampas tebu dan serbuk kayu dapat dijadikan sebagai bahan campuran insulator pada ruangan akomodasi kapal.

\section{METODE}

Langkah - langkah yang digunakan untuk menyelesaikan penelitian ini yaitu:

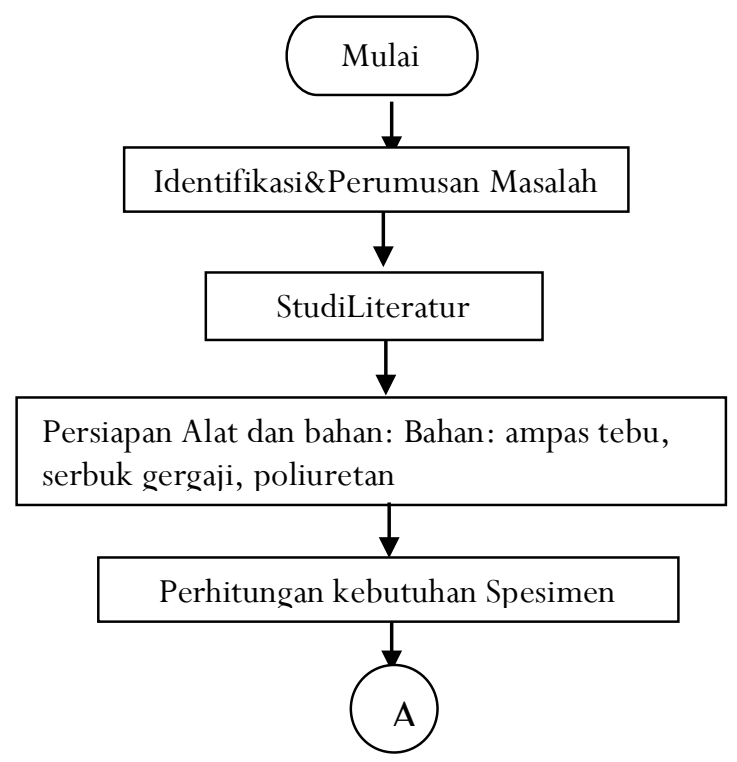

Gambar 1. Diagram AlirPenelitian

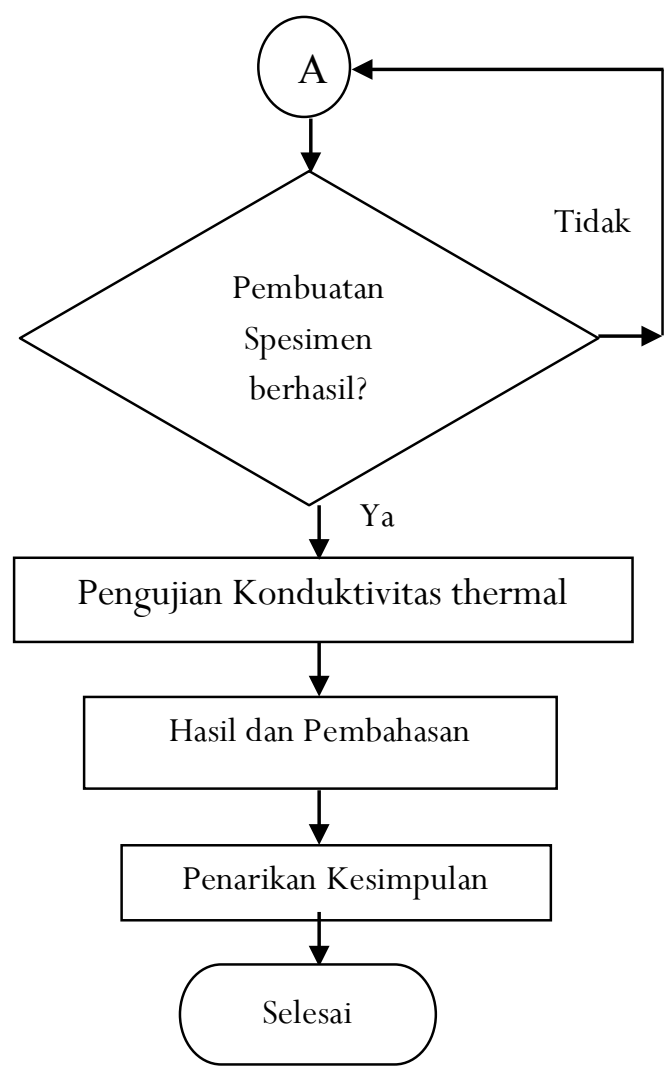

Gambar 2. Diagram AlirPenelitian (Lanjutan)

\section{a. Pembuatan Komposit}

Sebelum melakukan pembuatan komposit, tahapan yang dilakukan dalam pelaksanaan penelitian ini adalah:

1. Perbandingan Ekspansi

Penentuan perbandingan mengembang (ekspansi) berat campuran polyurethane terhadap volume dengan membentuk busa padat dengan mencampur larutan polyol dan isocynate $(1: 1)$ seperti yang telah dilakukan oleh Nasution (2014). Untuk membentuk volume $1 \mathrm{ml}$ masing-masing larutan (Polyol dan Isocynite), dengan berat larutan polyol 1,4123 gram dan Isocynite 1,8598 gram pada total berat kedua larutan setelah dicampur 3,2721 gram. Kedua larutan kemudian diaduk merata dan mengalami ekspansi maksimum selama 6'28' detik dengan membentuk volume polyurethane padat 14 $\mathrm{cm}^{3}$ dengan berat 15,5902 gram. Ini berarti bahwa. Larutan campuran mengalami ekspansi dengan volume 14 kali dari volume larutan awal dan membentuk 0,2337 $\mathrm{gr} / \mathrm{cm}^{3}$ seperti yang dilakukan oleh Nasution (2014). Penentuan perbandingan pada campuran polyurethane ini mengacu pada penelitian sebelumnya agar lebih fokus pada pemilihan serat alam untuk material insulasi. 
2. Persiapan Serbuk Kayu dan, Ampas tebu

Ampas tebu yang sudah didapatkan kemudian dikeringkan dengan cara dijemur secara alami menggunakan bantuan panas matahari. Ampas tebu dijemur pada suhu $30^{\circ} \mathrm{C}$ selama kurang lebih 35 jam agar kering. Ampas tebu yang telah kering kemudian dipotong kecil dengan panjang 5-10 mm untuk selanjutnya digiling menjadi serbuk ampas tebu.

Serbuk kayu yang sudah didapatkan dikeringkan terlebih dahulu dengan cara dijemur secara alami menggunakan bantuan panas matahari sampai serbuk kayu benar-benar kering.

\section{Perhitungan kebutuhan spesimen}

Pada tahap ini dilakukan perhitungan kebutuhan spesimen untuk mengetahui berapakah perbandingan yang tepat untuk memenuhi volume dari spesimen yang akan di uji.

\section{Pembuatan Spesimen}

Pada variasi komposisi pembuatan spesimen untuk polyurethane dan ampas tebu dibuat tetap (Fixed) sedangkan untuk serbuk kayu divariasikan. Spesimen dengan komposit polyurethane $40 \%$ atau dengan penambahan campuran serbuk kayu 60\% atau lebih besar, larutan polyurethane tidak dapat menyebar merata keseluruh bagian sisi dan menembus disela-sela ampas tebu dan serbuk kayu. Sehingga specimen tidak sempurna, dan mudah rusak dikarenakan minimnya bahan pengikat(polyurethane). Sehingga presentase perbandingan dari spesimen yang dilakukan adalah $60 \%$ polyurethane dan $40 \%$ komposit.

\section{b. Pengukuran Karakteristik Termal Properties \\ Pengukuran kondukivitas termal} berdasarkan ASTM C177. Pengujian dilakukan pada spesimen dengan meletakkan spesimen diatas plat panas dan dingin yang kemudian diukur dengan menggunakan thermokopel pada kedua sisi bagian dalam kedua plat. Pengukuran konduktivitas dilakukan dengan menempelkan probe thermokopel pada bagian dalam kedua plat dan memasukkan probe thermokopel ke bagian tengah specimen yang diapit oleh kedua plat tersebut. Pencatatan temperature dilakukan pada menit ke 150 secara seragam

\section{HASIL DAN PEMBAHASAN}

Pengujian diawali dengan pembuatan spesimen uji berbentuk silinder dengan ukuran $40 \times 50 \mathrm{~mm}$ dan mempunyai volume $62,8 \mathrm{~cm}^{3}$ dengan melakukan pencampuran serbuk kayu dan ampas tebu sebagai komposit pada perbandingan 60\% Polyurethane dan 40\% komposit, dimana untuk komposisi Polyurethane dan ampas tebu di buat sama setiap spesimen, sedangkan ampas tebu di variasikan. Untuk pencampuran 50\% Polyurethane dan 50\% komposit atau lebih besar tidak dapat dilakukan karena kurangnya cairan Polyurethane yang menyebabkan penggumpalan pada komposit sehingga tidak terjadi proses ekspansi sempurna.

Tabel 1. Kebutuhan spesimen dengan variasi:

\begin{tabular}{llllll}
\hline \multirow{2}{*}{$\begin{array}{l}\text { Spesim } \\
\text { en }\end{array}$} & \multicolumn{3}{c}{ Berat $(\mathrm{ml})$} & $\begin{array}{l}\text { Berat } \\
\text { serbuk }\end{array}$ & $\begin{array}{l}\text { Berat } \\
\text { ampas }\end{array}$ \\
\cline { 2 - 5 } & $\begin{array}{l}\text { PU } \\
\text { A }\end{array}$ & $\begin{array}{l}\text { PU } \\
\text { B }\end{array}$ & $\begin{array}{l}\text { PU } \\
\text { A+ } \\
\text { B }\end{array}$ & $\begin{array}{l}\text { Gergaji } \\
\text { (gr) }\end{array}$ & $\begin{array}{l}\text { tebu } \\
(\mathrm{gr})\end{array}$ \\
\hline 1 & 2,5 & 2,5 & 5 & 0,2 & 0,4 \\
2 & 2,5 & 2,5 & 5 & 0,4 & 0,4 \\
3 & 2,5 & 2,5 & 5 & 0,6 & 0,4 \\
4 & 2,5 & 2,5 & 5 & 0,8 & 0,4 \\
\hline
\end{tabular}

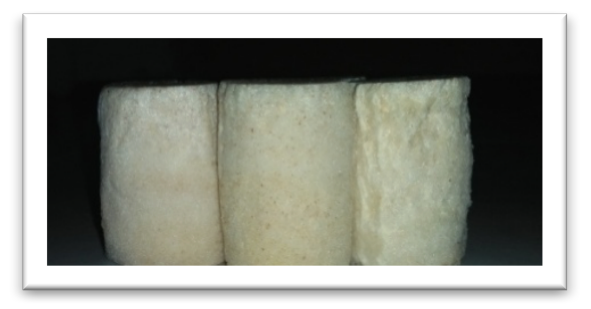

Gambar 3. Pembuatan spesimen

Pengukuran konduktifitas termal pada penelitian ini dilakukan untuk mengetahui kemampuan menghantarkan panas dari plat pemanas yang bersumber dari arus listrik sebesar 5,53 watt pada temperatur ruangan $29^{\circ} \mathrm{C}$. Berikut diperhatikan hasil dari pengukuran konduktifitas termal pada setiap spesimen komposit polyurethane-serbuk kayu-ampas tebu pada Tabel 2 .

Tabel 2. Pengukuran Temperatur dan Konduktivitas Spesimen.

\begin{tabular}{|c|c|c|c|c|c|c|c|c|}
\hline \multirow[t]{2}{*}{ sampel } & \multirow{2}{*}{$\begin{array}{c}\text { set poin } \\
\text { termocontrol }\end{array}$} & \multirow{2}{*}{$\begin{array}{l}\text { tegangan } \\
\text { (V) }\end{array}$} & \multirow{2}{*}{$\begin{array}{l}\text { Arus } \\
\text { (I) }\end{array}$} & \multicolumn{4}{|c|}{ Temperatur Tiap titik $\left({ }^{0} \mathrm{C}\right)$} & \multirow{2}{*}{$\begin{array}{l}\text { Konduktivitas } \\
\text { Termal } \\
(\mathrm{W} / \mathrm{Mk})\end{array}$} \\
\hline & & & & $\mathrm{T} 1$ & $\mathrm{~T} 2$ & $\mathrm{~T} 3$ & $\mathrm{~T} 4$ & \\
\hline 1 & 100 & 220 & 1.4 & 85 & 79.2 & 82.6 & 63 & 2.65 \\
\hline 2 & 100 & 220 & 1.4 & 89 & 88 & 86.6 & 64.2 & 2.28 \\
\hline 3 & 100 & 220 & 1.4 & 80.6 & 79.6 & 77.5 & 56 & 2.71 \\
\hline 4 & 100 & 220 & 1.4 & 78.4 & 77.4 & 74 & 55.2 & 2.76 \\
\hline
\end{tabular}

Berdasarkan hasil pengukuran yang didapat dari uji spesimen tersebut. Dilakukan perhitungan konduktivitas termal seperti yang ditunjukkan pada Tabel 2. Perbandingan konduktivitas termal setiap 
specimen komposit polyurethane - serbuk kayu Ampas tebu, lebih jelasnya dapat ditunjukkan pada Gambar 4.

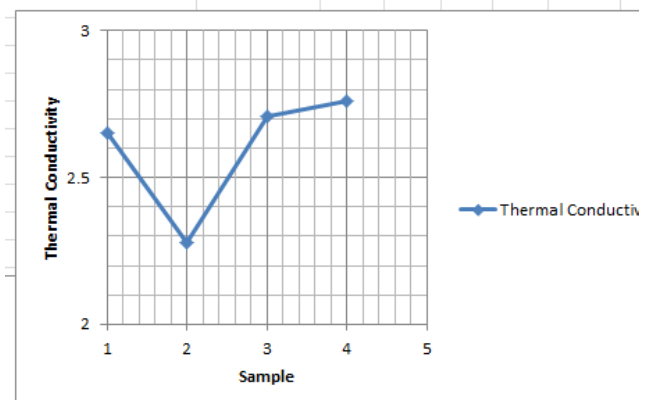

Gambar 4. konduktivitas termal setiap spesimen

Secara rata- rata semakin tinggi prosentase penambahan serbuk kayu pada spesimen komposit, maka nilai konduktifitas thermalnya semakin meningkat kecuali pada spesimen ke-2 nilai konduktifitas menurun karena kurangnya kalibrasi alat yang dilakukan dan pada saat pembuatan spesimen ke-2 pembuatan specimen kurang oprimal dan tidak memungkinkan untuk melakukan pengujian lagi. Sehingga berdasarkan penelitian sebelumnya dan hasil percobaan yang telah dilakukan dapat disimpulkan rata-rata didapatkan nilai konduktivitas terendah adalah pada pencampuran serbuk kayu 0,2 gr yaitu 2,65 w/mk. Nilai konduktivitas dari tiap spesimen tinggi diakibatkan oleh penggunaan tembaga sebagai penghantar panas yang mempunyai nilai konduktivitasnya tinggi yaitu $385 \mathrm{w} / \mathrm{mk}$, sedangkan sesuai dengan aplikasi untuk insulasi pada kapal seharusnya menggunakan baja karbon yang mempunyai nilai konduktivitas jauh lebih rendah dibandingkan tembaga yaitu 50w/mk. Hal tersebut dapat dilihat dari koefisien Konduktivitas pada tabel 3. Kalibrasi alat uji konduktivitas thermal diperlukan untuk memastikan keakuratan hasil pengujian, sehingga tidak terdapat kesalahan pada saat proses pengujian.

Tabel 3. konduktivitas termal (J. P. Holman,2010)

\begin{tabular}{ll}
\hline Material & $\begin{array}{l}\text { Konduktivitas termal } \\
\left(\mathrm{W} / \mathrm{M}^{0} \mathrm{C}\right)\end{array}$ \\
\hline Perak murni & 410 \\
Aluminium murni & 202 \\
Nekle murni & 93 \\
Besi Murni & 73 \\
Kayu & 0.17 \\
karet mentah & 0.15 \\
Arang kayu & 0.084 \\
Udara & 0.024 \\
\end{tabular}

Perhitungan Beban

a. Beban panas Transmisi (Qtr)

Setelah didapatkan nilai konduktivitas thermal terrendah pada percobaan tersebut yaitu pada pencampuran serbuk kayu 0,2 gr dengan nilai konduktifitas 2,65 w/mk, selanjutnya dilakukan perhitungan beban pendingin untuk mengetahui beban pendingin yang dapat ditahan oleh insulasi tersebut ruangan kapten diruang akomodasi kapal.

Berdasarkan Indian Standart (First Revision) 14754:2008 panas transmisi :

beban transmisi (Heat Transmission) diruang Akomodasi kapal:

$\emptyset=\Delta T(K v A v)+(K g A g)$

$\emptyset=$ Transmission Load

$\Delta T=$ Perbedaan tempertur luar dan dalam $(\mathrm{K})$

$\mathrm{K}_{\mathrm{v}}=$ Koefisien transfer panas $\left(\mathrm{W} / \mathrm{m}^{2} \mathrm{k}\right)$

$\mathrm{A}_{\mathrm{v}}=$ Luasan $\left(\mathrm{m}^{2}\right)$ tidak termasuk jendela $(\mathrm{kaca}+20 \mathrm{~mm})$

$\mathrm{K}_{\mathrm{g}}=$ Koefisien transfer panas $\left(\mathrm{W} / \mathrm{m}^{2} \mathrm{k}\right)$

$A_{v}=$ Luasan jendela $\left(\mathrm{m}^{2}\right)($ kaca $+20 \mathrm{~mm})$

Terdapat bebarapa bagian dalam menghitung beban panan transmisi antara lain: depan, belakang, kanan, kiri. Sehingga untuk perhitungan transmisi dapatditunjukanpadaTabel 4.

Tabel 4. Beban Transmisi Setiap Ruang Akomodasi

\begin{tabular}{lll}
\multicolumn{3}{c}{ Kapal } \\
\hline No & $\begin{array}{l}\text { Ruang akomodasi } \\
\text { kapal }\end{array}$ & BebanTransmisi \\
\hline 1 & Bagian depan & 39,6 watt \\
2 & Bagian belakang & 0,98 watt \\
3 & Bagian kanan & 8,153 watt \\
4 & Bagian kiri & 0,053 watt \\
\hline Q total & 48,782 watt \\
\hline
\end{tabular}

b. BebanPanas Orang (Qp)

Berdasarkan Indian Standart (First Revision) 14754:2008 kalor yg dikeluarkan orang terdapat dua jenis yaitu sensible heat dan latent heat, dan untuk nilai besar panas dari orang Berdasarkan Indian Standart (First Revision) 14754:2008. yaitu 120 Watt atau $0,12 \mathrm{Kw}$.

c. BebanPanasLampu (Ql)

Berdasarkan Indian Standart (First Revision) 14754:2008 menjelaskan bahwa untuk beban panas pada lampu dapat diabaikan jika perhitungan beban panas dilakukan pada siang hari, dan untuk tugas akhir ini perhitungan beban yang hitung pada kondisi siang hari 
sehingga nilai beban panas akibat lampu adalah 0 .

d. BebanPanasMatahari

Berdasarkan Indian Standart (First Revision) 14754:2008. Perhitungan panas matahari dapat dihitung dengan rumus:

$\emptyset=\sum A v k \Delta T r+\sum A g G s$

$\emptyset=$ beban panas matahari.

$\mathrm{A}_{\mathrm{v}}=$ Luasan yang dirambati panas $\left(\mathrm{m}^{2}\right)$.

$\mathrm{K}=$ koefisien panas berdasarkan (5.2.3) atau (5.2.4) untuk struktur kapal dalam permukaan $A_{v}$.

$\Delta T r=$ Temperatur yang lebih dari $35{ }^{\circ} \mathrm{C}$ tidak termasuk jendela.

$\Delta T r=12 \mathrm{~K}$ for vertical light surfaces.

$\mathrm{A}_{\mathrm{g}}=$ Luasan kaca yang terkena sinar matahari $\left(\mathrm{m}^{2}\right)$

$\mathrm{G}_{\mathrm{s}}=$ panas permukaan glass mengikuti:

$\mathrm{G}_{\mathrm{s}}=240 \mathrm{~W} / \mathrm{m}^{2}$ untuk luasan kaca dengan interior Sehingga berdasarkan perhitungaan menggunakan persamaan tersebut didapatkan seperti pada Tabel 5 .

Tabel 5. Beban Panas Setiap Bagian Akomodasi Panas

\begin{tabular}{lll}
\hline No & BagianAkomodasiKapal & Bebanpanas \\
\hline 1 & Bagiansisibelakangkamar & $155,7 \mathrm{~kW}$ \\
2 & BagianSisidepankamar & $155,7 \mathrm{kw}$ \\
\hline Total beban panas sinar matahari & $311 \mathrm{~kW}$ \\
\hline \multicolumn{3}{c}{ Berdasarkan perhitungan yang telah dilakukan }
\end{tabular}
maka didapatkan total beban pendingin yang terdapat dalam ruang tidur captain di ruang akomodasi yaitu:

Qtotal $=$ Qtr + Qp + Qi + Qs

$=0,048728 \mathrm{kw}+0,12 \mathrm{kw}+0+311 \mathrm{kw}$

$=311,59 \mathrm{kw}$

Berdasarkan hasil perhitungan tersebut didapatkan bahwa komposit dengan PU $5 \mathrm{ml}$, Ampas tebu 0,4 gr, dan serbuk kayu 0,2 gr, dapat menahan laju panas sampai $311,59 \mathrm{kw}$

\section{KESIMPULAN DAN SARAN}

Nilai konduktivitas terendah adalah pada pencampuran serbuk kayu 0,2 gr yaitu 2,65 $\mathrm{w} / \mathrm{mk}$. Berdasarkan hasil perhitungan tersebut didapatkan bahwa komposit dengan PU $5 \mathrm{ml}$, Ampas tebu 0,4 gr, dan serbuk kayu 0,2 gr, dapat menahan laju panas sampai $311,59 \mathrm{kw}$

\section{DAFTAR PUSTAKA}

Armanto, Yoga Eka. 2019. AnalisaKebutuhan Rockwool PadaInsulasiruangAkomodasi
KM

Pangalengan. TugasAkhirPoliteknikPerkapa lanNegeri Surabaya.

ASTM C 1045 - 97 “Standard Practice for Calculating Thermal Transmission Properties Under Steady State Conditions". Annual Book ASTM

ASTM C 518-98 “Standard Test Method for SteadyState Thermal Transmission Properties by Means of the Heat Flow Meter Apparatus”. Annual Book ASTM

Baharuddin, dkk. 2005. "Pemanfaatan Serbuk Kayu Jati (Tectona grandis L) Yang Direndam Dalam Air Dingin Sebagai Media Tumbuh Jamur Tiram (Pleorotus comunicipae)". Jurnal Perrenial: 2(1). 1-5.

IS 14754:2008 "Ships and marine technology - AirConditioning and Ventilation of accommodation space - Design conditions and basic of calculations" Firt Revision

J. P. Holman.1997. PerpindahanKalor. Jakarta :Erlangga Arikunto, S. 1998. ProsedurPenelitian. Jakarta: RinnekaCipta

J P Holman. "Heat Transfer". New York : McGrawHill Company (2010)

Maiwita,Fitria.,Darvina.Yenni., Yulkifli., 2014., "Pengaruh Variasi Komposisi Ampas Tebu Dan Serbuk Gergaji Pada Papan Partikel Terhadap Konduktivitas Termal”.PILLAR OF PHYSICS, Vol. 1. April 2014, 41-48

Nasution, P., Fitri, S, P., Semin. 2014. Karakteristik Sabut Kelapa Sebagai Insulator Palka Ikan, Berkala Perikanan Terubuk.Hal 82-92 ISSN 0126 - 426I.

Samsuri, M., M. Gozan, R. Mardias, M. Baiquni, H. Hermansyah, A. Wijanarko, B. Prasetya, dan M. Nasikin. 2007. Pemanfaatan selulosa bagas untuk produksi etanol melalui saka-rifikasi dan fermentasi serentak dengan en-zim xylanase. Makara Teknologi 11(1): 17-24.

Yosephine, Alita, Gala,Victor, Aning Ayucitra1*, Ery Susiany Retnoningtyas2.,2012 Pemanfaatan Ampas Tebu Dan Kulit Pisang Dalam Pembuatan Kertas Serat Campuran ., Jurnal Teknik Kimia Indonesia, Vol. 11, No. 2, 2012, 94-100. 